\section{Diminishing traditional methods and inaccessible modern healthcare: the dilemma of tribal health in India}

The dilemma of tribal health in India

\author{
Dandub Palzor Negi \\ Department of Social Work, Central University of Rajasthan, Ajmer, India, and \\ E.P. Abdul Azeez \\ Department of Social Work, Amity University Haryana, Gurgaon, India
}

\begin{abstract}
Purpose - This paper critically examines the state of tribal health in India by analyzing the accessibility and availability of traditional medicine and modern healthcare.

Design/methodology/approach - This essay is the product of an extensive review of the literature and authors' personal experience in working with the tribal communities.

Findings - The traditional medicinal practices once very prevalent among the tribal communities are diminishing due to various socio-economic, environmental and political factors. Modern healthcare in India's tribal region is characterized by a lack of availability, accessibility and affordability. As a result of the diminishing traditional practices and inaccessible modern healthcare provisions, tribal communities depend on quacks and magico-religious practices.

Originality/value - This essay advocates for urgent policy interventions to integrate traditional medicine and modern healthcare practices to address critical tribal health issues. Preservation of traditional medicinal knowledge-base and improving research in the field have the potential to address the health of tribal communities and of others. The accessibility and availability of modern healthcare facilities in tribal regions should be improved to ensure better health outcomes.
\end{abstract}

Keywords Traditional medicine, Tribal health, Indigenous communities, Healthcare accessibility, India Paper type Review

\section{Introduction}

Tribals in India constitute 104 million populations and belong to 705 ethnic groups. Around $89 \%$ of the tribals are located in rural areas, and the remaining live in urban areas [1]. Tribals in India show a bleak picture in terms of social development indicators, particularly health. This is because the general healthcare delivery system does not cater to their needs. India's tribal population remained out of national discourse and debate regarding health, education, poverty and other related social and human development indicators. Tribes face the disproportionate burden of communicable and non-communicable diseases, and it is further exacerbated by the poor healthcare infrastructure and facilities [2].

Tribals live in consonance and close connections with nature, and they follow a distinct way of life. Their indigenous way of life makes them different from other mainstream folks. Tribes have developed their institutions, customs and practices based on their cultural and

(C) Dandub Palzor Negi and E.P. Abdul Azeez. Published in Journal of Health Research. Published by Emerald Publishing Limited. This article is published under the Creative Commons Attribution (CC BY 4.0) licence. Anyone may reproduce, distribute, translate and create derivative works of this article (for both commercial and non-commercial purposes), subject to full attribution to the original publication and authors. The full terms of this licence may be seen at http://creativecommons.org/licences/by/4.0/ legalcode

The authors thank the anonymous reviewers for their valuable comments on the initial draft of the manuscript.
Received 8 January 2021

Revised 18 March 2021

Accepted 23 April 2021 
JHR

36,5

868

religious beliefs. The medicine system is one among them, which they have developed based on their traditional knowledge and associated beliefs [3]. Traditional medicinal practices have been in use since time immemorial. Various studies suggest that tribals use around 25,000 plant-based formulations [4]. Though there has been the intrusion of Western medicine among the tribals, traditional medicine survives in these communities [5]. This traditional knowledge is being transferred from one generation to another through oral tradition.

However, the traditional medicinal practices prevalent in the tribal communities are diminishing. Moreover, modern healthcare provisions are ill-equipped to reach the vast majority of the tribals. In this context, the present paper critically examines the state of tribal health in India by analyzing the accessibility and availability of traditional medicine and modern healthcare. This essay is framed out of the authors' experience in working with tribal population and reflections from the available evidence. In the initial part of the essay, we elucidate the state of tribal health in India. We examine the importance, tribals' dependency on traditional medicine and the emerging challenges. Then, we attempt to showcase the state of accessibility, availability and affordability issues of modern healthcare in India's tribal regions. This paper explores the present and future of tribal health and possible synergies and integration with the modern healthcare system.

\section{State of tribal health in India}

The tribal population shows alarming statistics on the health indicators. Life expectancy among the tribal population at birth is 63.9 years as against 67 years of the mainstream population $[2,5]$. An alarming condition is that $65 \%$ of tribal women between the ages of 15 and 49 are anaemic [2, 6]. As per National Sample Survey Office (NSSO) 2014, 27 percent of tribal women still deliver at home [7]. The infant mortality rate among the tribal population is 74 as against the 62 of the rest of the population [8]. Similarly, maternal mortality rate (MMR) is 57 (National Family Health Survey-4). Immunization of children is 55.7 percent compared to 71.6 percent among other population [9].

The tribal population suffers disproportionally in terms of the prevalence of communicable diseases. In all, $80 \%$ of malaria cases in the country are reported from tribal areas, accounting for $50 \%$ mortality [2]. The prevalence of pulmonary tuberculosis (TB) is significantly higher among the tribal population, which is 703 per 100,000 as against 256 per 100,000 of the country [10]. The highest case of tuberculosis in India is reported from the Sahariya tribe of Madhya Pradesh [11]. The proportion of leprosy was 18.5 percent among the tribals, which is also disproportionally high compared to the mainstream population [1]. The prevalence of non-communicable diseases such as hypertension, diabetes, cancer and cardiovascular ailments is also reported high in the tribal region $[12,13]$. Various studies have also reflected the grim condition of malnutrition among the tribes [14-18]. The genetic disorder such as sickle cell anaemia glucose-6-phosphate dehydrogenase (G6PD) is also reported among the several particularly vulnerable tribal groups (PVTGs) in India [19, 20]. Besides, there is a significant burden of diseases on the different tribal groups across the states. Tribal groups of Chattisgarh and Madhya Pradesh, such as Oraons, Gonds, Baigas, Kanwar, Bhumias and Manjhis, were reported with a high incidence of diseases such as tuberculosis, leprosy, malaria, epilepsy, sickle cell disease, diabetes mellitus and cancer [21]. Similarly, the prevalence of sickle cell disorders is higher among tribal groups such as Bhil, Pawara, Korku, Otkar, Madia and Pardhan of Maharashtra [20]. Sexually transmitted diseases (STIs) are also prevalent among the tribes of Rajasthan [22]. Besides tuberculosis, malaria, STDs and the prevalence of malnutrition among the Bondo, Juang, Didayi and Kutia Kondh tribes of Orrisa are high; G6PD deficiency is also high among the Munda, Paraja, Kharia, Bhuyan, Santhal and Oroan [13] people.

However, the data on the health conditions of tribals across states are limited and bleak. The pattern of diseases also varies from region to region [19]. The illness pattern is shaped 
and reshaped by social and cultural practices and ecological niches that provide a different landscape and diversity. Further, the lack of adequate data sets on the illness patterns among the tribes poses a serious challenge before the policy-makers to address this issue.

For decades, the constant neglect and deprivation of tribes from policy perspectives has resulted in prevalence of several diseases among the tribals. In the policy frameworks, tribal healthcare usually comes under the ambit of rural health. Moreover, it would be inappropriate to assume that healthcare needs and the requirements of the tribal are similar to that of the rural populace. They have different habitats, environments and distinct social systems and cultures, leading to different healthcare needs and requirements. Hence, it needs a different approach to address these issues.

\section{Traditional medicine: the tribals' dependency and the challenges}

In India, traditional medicine has been in practice for centuries. The accounts of traditional medicine can be found in ancient Vedas and scriptures [23]. It is still a widely used modality of treatment and cure of various physical ailments. It is estimated that almost $80 \%$ of the population in Africa and Asia still uses traditional medicine or remedies rather than modern medicine for primary healthcare [24].

WHO defines traditional medicine as the knowledge or practices used in diagnosing, preventing or eliminating physical, mental or social disease, which may rely exclusively on experience or observations handed down from generation to generation, verbally or in writing [25]. This is similar to modern science, where hypothesis, trial, conclusion and more hypotheses are generated. This knowledge and treatment techniques are usually known as "alternative" or "complementary" or "ethnomedicine" [26] when used outside its traditional culture [27]. In India, numerous indigenous communities are claimed to be the guardians of traditional knowledge-based healthcare [28]. There are two streams of traditional medicine practised in India: classical and folk streams. The classical streams (Ayurveda, Siddha, Unani) of medicine are codified and well documented. On the other hand, folk streams of medicine are uncodified and sustained through oral tradition [4, 29].

Ever since the introduction of the modern healthcare system in the mainstream, traditional medicine is somewhat neglected and often criticized for being unscientific and irrational. However, we have seen an attitudinal shift in recent years. Traditional medicine is now practised side by side with modern medicine in different countries across the world [25]. Tribals have developed a robust traditional medicine system based on their knowledge through observation and reasoning from time immemorial [27]. Not only tribes but also the majority of the rural population uses traditional medicine for treatment in India. Millions of traditional practitioners use this traditional healing method [29]. Recent evidence suggests that tribal communities are equipped with traditional medicine knowledge and primarily rely upon it [30-32].

The prevailing social norms, beliefs, cultural practices, geographical isolation and forest dependency push the tribal population to seek traditional methods. The examination of the literature on tribal health in India reveals the following crucial factors of traditional medicine's popularity.

\section{Availability}

The first thing which makes traditional methods popular among tribes is its availability. Different plants and herbs are used for treating various ailments. It is estimated that more than 25,000 plant-based formulations are used in traditional medicine [4, 33, 34]. These plants are readily available in their locality [30,35], and at least one or more people know the medicinal values of herbs and plants in the tribal regions. 
Traditional medicine is well integrated into the tribe's beliefs and practices [36, 37], making it an accepted way of life. Indigenous way of life and their proximity with nature could sustain traditional wisdom and knowledge. Indigenous or traditional medicine and practices have always been accepted throughout human culture and civilization [38].

Traditional medicine is widely used due to its affordability. Due to malpractices and informal payments, tribals are choosing traditional medicine over modern one [39]. Moreover, traditional medicine or practitioners are cheap and affordable and a viable alternative [40] in the absence of modern or Western healthcare.

On the other hand, traditional healthcare based on traditional medicine has its distinct challenges across regions and countries. According to Cordell and Colvard, the following are the challenges concerning traditional medicine practice [41].

(1) Nations typically have no policies or regulations relating to all of the aspects of traditional medicine as an integral part of their overall healthcare system. This results in a minimal commitment to research and development funding.

(2) Global attention (fiscal and human resources) is insufficient to enhance traditional medicine's basic, applied and clinical aspects. This results in significant deficiencies in the scientific evidence regarding the quality, safety, effectiveness and health benefits of traditional medicine.

(3) Formal training programmes and associated standards for learning and licencing of practitioners may not be available. Regulations regarding practitioner training are quite different between nations.

(4) Standards for traditional medicine products and practices, including terminology and philosophical approaches, are highly varied. This limits communication and efforts to harmonize systems between nations.

(5) The literature and knowledge regarding traditional medicine are highly scattered or are in library collections and databases that are not easily accessible.

(6) Scientific and clinical research on traditional medicines does not always fit the Western model for medical research, making the publication of results difficult. Health insurance coverage is complicated to justify if traditional medicine products and practices are not evidence-based.

Above-cited challenges are pertinent and applicable to the Indian context. These policy-and research-level challenges prevent the mainstreaming of traditional medicine practices in India. The same is largely impacting the tribal population, who are mainly relying on such practices.

Further, the plants used for medicinal formulations are also on the verge of extinction due to over-exploitation of nature in the tribal regions in the name of development. Forest and land degradation are prominent issues impacting medicinal plants' availability and traditional medicinal practices [42-44]. Laws restricting access of the tribals to the forest also impact traditional medicine practices [45]. It is also reported that some of the important medicinal plants in India are on the verge of extinction [46, 47]. Evidence also suggests that the tribal population's development-induced displacement results in losing their close affinity with nature and, eventually, their knowledge of traditional medicine and its practice [48, 49]. Various policies initiated in the name of protection of forest and tribal's interest negatively impact their access to the forest $[50,51]$ and hence the traditional way of life. It can be 
underlined from the available evidence that various factors now impact tribal society's dependence on traditional methods.

The magico-religious mode of treatment and cure is still prevalent among the tribes, and the diminishing practices of traditional medicine will further strengthen such practices [22, 52-55]. Traditional medicine, magico-religious practice and quackery differ from each other. Traditional medicine is based on experience, and on empiricism to some extent. The magicoreligious practices, however, have nothing to do with science and evidence. Traditional methods and magico-religious techniques are practised in a blended manner by many The dilemma of tribal health in India practitioners. The quackery is a recent addition to this blending. The degradation of traditional knowledge-base and practices have led the tribals to depend on magico-religious practices and quackery [37]. Moreover, the mushrooming of quackery practices and tribals' dependency on them will significantly negatively impact the tribals' health outcomes.

\section{Modern healthcare in the tribal regions of India: ailments and inaccessibility}

Modern healthcare has made a significant advancement across the world in the recent past. Scientific innovation and technological advancement resulted in new and innovative ways of treating the illness. Progress in medical science has led to increased life expectancy and decreased mortality. Despite such an enormous and incredible advancement, accessibility remains an important issue for many people across nations. It is a matter of concern for global policymakers. Therefore, to promote every individual's well-being globally, WHO in 1998 has made a global health policy for achieving health for all in the 21st century, emphasizing health security, accessibility to quality healthcare and health equity. However, modern medicine has still not reached to all individuals. The majority of the developing and underdeveloped countries do not have access to modern healthcare [56]. It is true in the case of indigenous populations of India. Tribals habitat in remote and unreachable areas, making it almost impossible for them to access healthcare services. Therefore, many of them have for a long time relied only on traditional medicine.

One of the perturbing factors regarding modern healthcare in the tribal region is a shortage of modern healthcare human resources and infrastructure. There is a deficit of 1,240 primary health centres (PHCs), 273 community health centres (CHCs) and 6,503 sub-centres (SCs) in the tribal region of the country. Madhya Pradesh, Jharkhand and Rajasthan top the list in having the highest deficit, that is, 381 (PHCs), 228 (PHCs) and 225 (PHCs), respectively, in the region [57]. There is also a significant shortfall of doctors and nursing staff in PHCs in the tribal areas.

Additionally, there is a wide disparity in healthcare delivery in rural and urban India. A large population of $65 \%$ lives in rural areas, with less or no access to quality healthcare compared with the urban populace in India. Resultantly, this population ultimately resorts to traditional or alternative medicine. Secondly, most rural people (including tribals) live below the poverty line and cannot afford or bear medical expenditure. Moreover, out-of-pocket expenditure on healthcare is high in India. Consequently, there is increased impoverishment, and it adds more people to below the poverty line. It is estimated that $8 \%$ of the country's population is pushed to poverty due to increased out-of-pocket health expenditure [58].

There may be myriad challenges to the modern medical system delivery in the tribal regions that need a systematic and planned solution at every level of operation and governance. We will now focus on three significant challenges to public healthcare in India's tribal regions. First is the issue of accessibility. Accessibility is one of the primary principles of Alma-Ata's declaration on primary healthcare [59]. Access to healthcare encompasses different dimensions such as service availability, utilization of services, relevance and effectiveness and equity [60]. All these dimensions of accessibility in the tribal regions are appalling, leading to a poor health outcome $-25 \%$ of the tribal population does not have 
JHR

36,5

proper access to healthcare [57]. Additionally, physical distance is another issue in availing the services. As per the Comptroller and Auditor General India (CAG) report, the health centres are built in inaccessible and uninhabited locations in the tribal areas of Rajasthan, which pose severe challenges in accessing the services [61].

Geographically distant and scattered habitat with steep terrain often makes it very difficult to access and avail transport facilities for health centres. Additionally, poor public/ private transport, ambulance services, language barriers and lack of access to money add more obstacles to accessibility [62]. Besides, the quality of healthcare also matters. Lack of proper infrastructure, lack of necessary medicines and no proper medical equipment are hurdles in accessing healthcare services.

Secondly, the human resource crunch in the public health institutions is distressing in the tribal belts across states. Though India has developed a robust healthcare system across the country's various regions to cater to its citizens' health needs, health outcome is far behind the set goals [63]. Human resources for health is varied across regions in India. Rural Health Statistics (2018-19) reported an enormous shortfall of healthcare personnel in the PHCs, SCs and CHCs located in the tribal areas of different states/UTs [57]. Further, the Ministry of Tribal Affairs reports that $82.3 \%$ of specialists positions in $\mathrm{CHCs}, 32.6 \%$ of technicians and $27.9 \%$ of nurse posts in CHCs and PHCs were vacant in 2017 [58]. This aggravates the health outcome in the regions, resulting in poor health indicators, and widespread disease often goes untreated. Understaffed health personnel or the absence of it impedes the community's health and makes them more vulnerable to infections.

Third is the financial constraint. As predominantly tribal population lives below the poverty line and faces abject poverty. As per the National Family Health Survey 2015-16 (NFHS-4) data, $45.9 \%$ of the tribal population were in the lowest wealth bracket [4]. It is harder for this indigent populace to access healthcare. Financial constraint is one of the substantial barriers to healthcare utilization. Moreover, a poor household cannot bear the expenses of medicine. Although the government provides free medicine and health checkup in many states, certain medications have to be purchased from private clinics.

Moreover, the lack of technicians in the government healthcare centres forces tribals to avail the private clinics or laboratories for clinical test or diagnosis, which are heavy on their pockets; the absence or less regulatory provisions of these private clinics result in them charging high fees. Consequently, it puts a burden on the family's income, for which they have to take a loan from the local money lenders by mortgaging their properties, which has long-term repercussions. Many low-income families depend on informal practitioners or quack for healthcare due to poor public healthcare delivery [64].

\section{The way forward}

India's healthcare presents a varied spectrum of contrasting factors and landscape. On the one hand, it is well-equipped with advanced facilities and is available to the privileged urban population. On the other side, it shows a bleak picture with inadequate and ill-equipped health infrastructure, mostly in rural (including tribal) areas. This gap or inequality in urban-rural healthcare is likely to increase if proper policy-level changes are not implemented. The case of the tribal population is very critical in this regard. The diminished traditional medicinal practices impact tribals due to various socio-economic, environmental and policy factors. Modern healthcare is ill-equipped to address the healthcare needs of the tribals. Amid the emerging health complexities, tribal society remains one of the most vulnerable segments of the population.

Healthcare to the most deprived section of the society has its own challenges and demands. There is widespread inequality in terms of the accessibility, availability and affordability of modern healthcare to most rural and tribal populations. Accessibility remains 
the issue in remote or far-flung areas, with almost no or poor road connectivity and minuscule transport facilities. The non-availability of good healthcare services in the regions results in increased morbidity and mortality. Furthermore, it also leads to specific unscientific modalities of treatment such as quacks and sorcery.

Regarding traditional medicine, there is less or no clinical evidence on the effectiveness of its usage. Moreover, traditional medicine has been neglected in the field of health and medicine. The world has recently witnessed a resurgence in traditional medicine based on plant formulations and herbs due to modern medicine's side effects [4]. World Health Organization (WHO) developed Traditional Medicine Strategy 2014-2023 and emphasized integrating traditional and complementary medicine in the national health system to promote universal healthcare and ensure the quality, safety and effectiveness of such medicine.

Considering all these fallacies and challenges, the Government of India (GOI) should spend an adequate percent of per capita expenditure on tribal health, mainly focusing on primary healthcare. The human resource crunch in the public healthcare institutions, mainly in PHCs and $\mathrm{CHCs}$, should be resolved by training an exceptional cadre of doctors for tribal areas. Besides this, mobile healthcare, a camp-based approach at regular intervals and special training for paramedical staff could be initiated to minimize accessibility and availability issues. India relatively has a long statistical tradition concerning tribal peoples and other marginalized groups. Many countries lack such traditions. However, data, particularly concerning health aspects of the tribals, are inadequate in the Indian context. Hence, the data inadequacy related to tribal health, illness, availability and accessibility should be addressed. The government must ensure measures to improve the data system at different levels, including the documentation of traditional methods.

It is imperative to integrate traditional medicine into India's primary healthcare to meet universal access to equitable, affordable and quality healthcare to people, including the marginalized section, as envisaged in the National Health Mission. Additionally, multidisciplinary research and clinical trials must be encouraged to further the scope and application of traditional knowledge into modern healthcare. A robust system of documentation is also pertinent to retain the traditional knowledge-base. Though the GOI is leaving no stone unturned in the development and protection of the rights of its tribal people, tribals are lagging in various development indicators, especially in health. The government should work to implement the guidelines and framework provided by the United Nations Declaration on the Rights of Indigenous Peoples (UNDRIP), promote, preserve and protect the rights of tribal people, especially the right to fair access to healthcare and the right to use and practise traditional medicine. Besides, the government should impart cultural competency training for medical and paramedical professionals to enhance their skills and connectedness with the indigenous population. Cultural competence training is of paramount significance in improving the health outcome, and it helps healthcare providers to understand the social and cultural meaning of health and illness. Subsequently, it helps in reducing health disparities and misconceptions regarding ethnic minority such as indigenous peoples.

\section{Conclusion}

Despite significant growth and expansion, India's healthcare services do not cater to the needs of the week and marginalized communities of the country. Existing healthcare inequalities in terms of accessibility, availability and affordability among the vast rural and urban population become a policy-level challenge for the state and central governments to tackle. Inadequate health infrastructure and human resource further aggravate the situation. Healthcare is not only in an abysmal state, but it is also catastrophic to the families living on society's margins [65]. The broad spectrum of healthcare inequalities in terms of accessibility, 
JHR

36,5

affordability and availability across India's regions poses a myriad of challenges in achieving health for all in the 21st century.

Treatment modalities based on traditional knowledge of herbs and plants in the tribal region is on the verge of extinction. The irony is that folk medicine is not adequately documented [4]. One reason for the cessation of this knowledge is the uncontrolled exploitation of nature and the environment in the name of development. There is a growing need for traditional medicine across countries in the world. WHO has developed a strategy the WHO Traditional Medicine Strategy 2014-2023 - which will help countries develop the solutions that will improve healthcare by formulating a policy to integrate traditional medicine into modern medicine [66]. Therefore, India should develop a tribal health policy with a strong emphasis on promoting and integrating traditional medicine into modern healthcare to resolve the human resource crunch and strengthen the long tradition of indigenous medicine knowledge that will reach everyone.

Conflict of Interest: None

\section{References}

1. Census of India 2011 provisional population totals. New Delhi: Office of the Registrar General and Census Commissioner; 2011.

2. India, Ministry of Health and Family Welfare; Ministry of Tribal Affairs. Report of the expert committee on tribal health: tribal health in India: bridging the gap and roadmap for the future. Policy brief. [cited 2020 May 9]. Available from: http://nhsrcindia.org/news/report-expertcommittee-tribal-health.

3. Negi DP, Singh MM. Tribal health in India: a need for a comprehensive health policy. Int J Health Sci Res. 2019; 9(3): 299-305.

4. Sen S, Chakraborty R. Toward the integration and advancement of herbal medicine: a focus on traditional Indian medicine. Botanics. 2015; 5: 33-44. doi: 10.2147/BTAT.S66308.

5. Anderson I, Robson B, Connolly M, Al-Yaman F, Bjertness E, King A, et al. Indigenous and tribal peoples' health (The Lancet-Lowitja Institute Global Collaboration): a population study. Lancet. 2016; 388(10040): 131-57. doi: 10.1016/S0140-6736(16)00345-7.

6. International Institute for Population Sciences [IIPS]. National family health survey (NFHS-3), 200-06: India. Mumbai: IIPS; 2007.

7. National Sample Survey Office [NSSO]. Key indicators of social consumption in India: health. (NSSO 71st round, January-June 2014). New Delhi: NSSO; 2015.

8. National family health survey (NFHS-4) 2012-14. [cited 2020 May 9]. Available from: http://www. rchiips.org/nfhs/nfhs4.shtml.

9. India, Ministry of Women and Child Development. Rapid survey on children (RSOC) 2013-14. [cited 2020 May 9]. Available from: https://wcd.nic.in/acts/rapid-survey-children-rsoc-2013-14.

10. Thomas BE, Adinarayanan S, Manogaran C, Swaminathan S. Pulmonary tuberculosis among tribals in India: a systematic review \& meta-analysis. Indian J Med Res. 2015; 141(5): 614-23. doi: 10.4103/0971-5916.159545.

11. Swaminathan S. Taking healthcare to India's remote tribes. The Hindu. [updated 2014 Sep; cited 2020 May 9]. Available from: https://www.thehindu.com/opinion/op-ed/taking-healthcare-toindias-remote-tribes/article6370400.ece.

12. Narain JP. Health of tribal populations in India: how long can we afford to neglect? Indian J Med Res. 2019; 149(3): 313-6. doi: 10.4103/ijmr.IJMR_2079_18.

13. Balgir RS. Tribal health problems, disease burden and ameliorative challenges in tribal communities with special emphasis on tribes of Orissa. In: Proceedings of National Symposium on "Tribal Health"; 2006 October 19-20; Jaipur, India. Jabalpur: Regional Medical Research Centre for Tribals, Indian Council of Medical Research; 2007. p. 161-76. 
14. Debnath A, Bhattacharjee N. Factors associated with malnutrition among tribal children in India: a non-parametric approach. J Trop Pediatr. 2014; 60(3): 211-5. doi: 10.1093/tropej/fmt106.

15. Van de Poel E, Speybroeck N. Decomposing malnutrition inequalities between Scheduled Castes and Tribes and the remaining Indian population. Ethn. Health. 2009; 14(3): 271-87. doi: 10.1080/ 13557850802609931.

16. Talapalliwar MR, Garg BS. Nutritional status and its correlates among tribal children of Melghat, central India. Indian J. Pediatr. 2014; 81(11): 1151-7. doi: 10.1007/s12098-014-1358-y.

17. Singh M, Chakravarty R, Bhanotra A, Kumar M. Dairy animal health and housing management practices followed by tribal dairy farmers of Ranchi, Jharkhand. Int J of Farm Sci. 2015; 5(3): 199-206.

18. Choudhary HR, Abdul Azeez EP. The Korku tribe of Melghat region in India and their current state: an ethnographic study. Orient Anthropol. 2020; 20(1): 97-112. doi: 10.1177/ 0972558X20913700.

19. Basu S. Dimensions of tribal health in India. Health Popul Perspect Issues. 2000; 23(2): 61-70.

20. Kate SL. Health problems of tribal population groups from the state of Maharashtra. Indian J Med Sci. 2001; 55(2): 99-108.

21. Jain Y, Kataria R, Patil S, Kadam S, Kataria A, Jain R, et al. Burden \& pattern of illnesses among the tribal communities in central India: a report from a community health programme. Indian J Med Res. 2015; 141(5): 663-72. doi: 10.4103/0971-5916.159582.

22. Kushwah VS, Sisodia R, Bhatnagar C. Magico-religious and social belief of tribals of district Udaipur, Rajasthan. J Ethnobiol Ethnomed. 2017; 13(1): 69. doi: 10.1186/s13002-017-0195-2.

23. Pandey MM, Rastogi S, Rawat AK. Indian traditional ayurvedic system of medicine and nutritional supplementation. Evid Based Complement Alternat Med. 2013; 2013: 376327. doi: 10. 1155/2013/376327.

24. Shetty P. Integrating modern and traditional medicine: facts and figures. [updated $2010 \mathrm{My} 27$; cited 2020 May 10]. Available from: https://www.scidev.net/global/features/integrating-modernand-traditional-medicine-facts-and-figures/.

25. World Health Organization [WHO]. Declaration of Alma Ata: international conference on primary health care, Alma Ata, USSR, 6-12 September 1978. [cited 2020 May 9]. Available from: https:// apps.who.int/iris/handle/10665/39228.

26. Yuan $\mathrm{H}$, Ma Q, Ye L, Piao G. The traditional medicine and modern medicine from natural products. Molecules. 2016; 21(5). doi: 10.3390/molecules21050559.

27. Che CT, George V, Ijinu TP, Pushpangadan P, Andrae-Marobela K. Traditional medicine. In: Badal S, Delgoda R, editors. Pharmacognosy. Boston: Academic Press; 2017. p. 15-30.

28. Reddy S. Making heritage legible: who owns traditional medical knowledge?. Int J Cult Prop. 2006; 13(2): 161-88. doi: 10.1017/S0940739106060115.

29. Sudha PS. Interface between traditional knowledge (TK) and human rights in realizing right to health and health care-an Indian perspective. Peace Human Rights Governance. 2018; 2(3): 331-45. doi: 10.14658/pupj-phrg-2018-3-3.

30. Raj AJ, Biswakarma S, Pala NA, Shukla G, Vineeta, Kumar M, et al. Indigenous uses of ethnomedicinal plants among forest-dependent communities of Northern Bengal, India. J Ethnobiol Ethnomed. 2018; 14(1): 8. doi: 10.1186/s13002-018-0208-9.

31. Uniyal SK, Singh KN, Jamwal P, Lal B. Traditional use of medicinal plants among the tribal communities of Chhota Bhangal, Western Himalaya. J Ethnobiol Ethnomed. 2006; 2: 14. doi: 10. 1186/1746-4269-2-14.

32. Debbarma M, Pala NA, Kumar M, Bussmann RW. Traditional knowledge of medicinal plants in tribes of Tripura in Northeast, India. Afr J Tradit Complement Altern Med. 2017; 14(4): 156-68. doi: 10.21010/ajtcam.v14i4.19.
The dilemma of tribal health in India 
JHR

36,5

33. Sen S, Chakraborty R. Revival, modernization and integration of Indian traditional herbal medicine in clinical practice: importance, challenges and future. J Tradit Complement Med. 2017; 7(2): 234-44. doi: 10.1016/j.jtcme.2016.05.006.

34. Patra JK, Das G, Kumar S, Thatoi HN (Eds). Ethnopharmacology and biodiversity of medicinal plants. Palm Bay, Florida, FL: Apple Academic Press; 2019.

35. Das S, Bose K. Adult tribal malnutrition in India: an anthropometric and socio-demographic review. Anthropol Rev. 2015; 78(1): 47-65. doi:10.1515/anre-2015-0004.

36. Guite N, Acharya SS. Indigenous medicinal substances and health care: a study among Paite tribe of Manipur, India. Stud. Tribes Tribals. 2006; 4(2): 1-10. doi: 10.1080/0972639X.2006.11886541.

37. Negi DP, Singh MM. Tribal health and health care beliefs in India: a systematic review. Int J Res Soc Sci. 2018; 8(1): 219-26.

38. Datta T, Patra AK, Dastidar SG. Medicinal plants used by tribal population of Coochbehar district, West Bengal, India-an ethnobotanical survey. Asian Pac J Trop Biomed. 2014; 4(Suppl 1): S478-82. doi: 10.12980/apjtb.4.2014c1122.

39. Ramalingareddy K. Improving health services for tribal populations. Int J Res Soc Sci. 2016; 6(11): 345-57.

40. Debas HT, Laxminarayan R, Straus SE. Complementary and alternative medicine. In: Jamison DT, Breman JG, Measham AR, Alleyne G, Claeson M, Evans DB, et al., editors. Disease control priorities in developing countries. 2nd ed. Washington, DC: The International Bank for Reconstruction and Development/The World Bank; 2006. p. 1281-91.

41. Cordell GA, Colvard MD. Natural products and traditional medicine: turning on a paradigm. J Nat Prod. 2012; 75(3): 514-25. doi: 10.1021/np200803m.

42. Banerjee A, Madhurima C. Forest degradation and livelihood of local communities in India: a human rights approach. J Hortic For. 2013; 5(8): 122-9. doi: 10.5897/JHF2013.0305.

43. Kiran, KR, Rani M, Pal A. Reclaiming degraded land in India through the cultivation of medicinal plants. Botany Res Int. 2009; 2(3): 174-81.

44. Dwivedi S, Dwivedi A, Dwivedi SN. Folk lore uses of some plants by the tribes of Madhya Pradesh with special reference to their conservation. Ethnobotanical Leaflets. 2008; 12(1): 763-71.

45. Abdul Azeez EP, Sebastian A. Development and Cultural distortion: assessing the impacts of development programmes and policies on medicinal practice of Baiga community of Chhattisgarh. Contemporary Voice of Dalit. 2016; 8(1): 82-9. doi: 10.1177/2455328X16628612.

46. Heywood VH, Iriondo JM. Plant conservation: old problems, new perspectives. Biol Conserv. 2003; 113(3): 321-35. doi: 10.1016/S0006-3207(03)00121-6.

47. Hamilton AC. Medicinal plants in conservation and development case studies and lessons learnt. Salisbury: Plantlife International; 2008.

48. Abdul Azeez EP, Saini P, Negi DP. Mapping the price of development induced displacement: a study on displaced of Sariska tiger reserve in Rajasthan, India. J Community Posit Pract. 2014; 14(2): 50-60.

49. Joseph A, Beegom RKB. Cultural genocide among tribals: an excrescence of development induced displacement. Herit: J Multidiscip Stud Archaeol. 2017; 5: 620-30.

50. Kulkarni S. Forest Legislation and tribals: comments on forest policy resolution. Econ Polit Wkly. 1987; 22(50): 2143-8.

51. Mukherjee SS. Indian forest act and democracy: effect on the traditional tribal system. [cited 2020 May 12]. Available from: http://www.mainstreamweekly.net/article6363.html.

52. Basu SK. A health profile of tribal India. Health Millions. 1994; 2(2): 12-4.

53. Jain S, Agrawal S. Perception of illness and health care among Bhils: a study of Udaipur district in Southern Rajasthan. Stud. Tribes Tribals. 2005; 3(1): 15-9. doi: 10.1080/0972639X.2005.11886515.

54. Bhasin V. Traditional medicine among tribals of Rajasthan. J Soc Sci. 2002; 6(3): 153-72. doi: 10. 1080/09718923.2002.11892345. 
55. Bhasin V. Health status of tribals of Rajasthan. Stud. Ethno-Med. 2007; 1(2): 91-125. doi: 10.1080/ 09735070.2007.11886304.

56. India, Ministry of Tribal Affairs. Report of the standing committee on social justice and empowerment. [cited 2020 May 12]. Available from: http://164.100.47.193/lsscommittee/Social\% 20Justice \%20\&\%20Empowerment/16_Social_Justice_And_Empowerment_63.pdf.

57. Government of India, Ministry of Health and Family Welfare [MoHFW]. Rural health statistics, 2018-19. New Delhi: MoHFW; 2019.

58. Kumar K, Singh A, Kumar S, Ram F, Singh A, Ram U, et al. Socio-economic differentials in tribal health in India impoverishment effects of out-of-pocket health expenditure in China and India: evidence from WHO SAGE. PLoS One. 2015; 10(8): e0135051. doi: 10.1371/journal.pone.0135051.

59. Shrivastava SR, Shrivastava PS, Ramasamy J. Implementation of public health practices in tribal populations of India: challenges and remedies. Healthc Low Resour Settings. 2013; 1(1): e3. doi: 10. 4081/hls.2013.e3.

60. Gulliford M, Figueroa-Munoz J, Morgan M, Hughes D, Gibson B, Beech R, et al. What does 'access to health care' mean?. J Health Serv Res Policy. 2002; 7(3): 186-8. doi: 10.1258/135581902760082517.

61. Hindustan Times. Provide accessible healthcare in rural areas, CAG tells Rajasthan govt. [updated 2017 Apr 1; cited 2020 May 18]. Available from: https://www.hindustantimes.com/jaipur/provideaccessible-healthcare-in-rural-areas-cag-tells-rajasthan-govt/story-4zDflT3SA2WMDBmROj o8hI.html.

62. Mavalankar D. Doctors for tribal areas: issues and solutions. Indian J Community Med. 2016; 41(3): 172-6. doi: 10.4103/0970-0218.183587.

63. Nandan D, Nair KS, Datta U. Human resources for public health in India-issues and challenges. Health Popul Perspect Issues. 2007; 30(4): 230-42.

64. Abdul Azeez EP, Anbu Selvi G, Sharma G, Senthil Kumar AP. What attracts and sustain urban poor to informal healthcare practitioners? A study on practitioners' perspectives and patients' experiences in an Indian city. Int J Health Plann Manage. 2021; 36(1): 83-99. doi: 10.1002/hpm.3068.

65. Zodpey S, Farooqui HH. Universal health coverage in India: progress achieved \& the way forward. Indian J Med Res. 2018; 147(4): 327-9. doi: 10.4103/ijmr.IJMR_616_18.

66. World Health Organization [WHO]. WHO traditional medicine strategy: 2014-2023. Geneva: WHO; 2013.

\section{Corresponding author}

E.P. Abdul Azeez can be contacted at: instinct000@gmail.com

For instructions on how to order reprints of this article, please visit our website:

www.emeraldgrouppublishing.com/licensing/reprints.htm

Or contact us for further details: permissions@emeraldinsight.com 